\title{
Glaucoma and diabetes: A review
}

\author{
Shweta Tripathi ${ }^{1, *}$, M Srinivasan $^{2}$ \\ ${ }^{1}$ Senior Consultant, Glaucoma services Indira Gandhi Eye Hospital and Research Centre Lucknow Uttar Pradesh, ${ }^{2}$ Formlely \\ Professor, Dept. of Ophthalmology, Mada Medical College Chennai, Tamil Nadu, India
}

\section{*Corresponding Author:}

Email: ssaishweta@rediffmail.com

\begin{abstract}
Glaucoma is ranked second amongst the causes of irreversible blindness worldwide. Diabetes mellitus (DM) is a global public health concern with numerous microvascular complications. There is increasing evidence to suggest that diabetic patients have greater risk of glaucoma as well.

This review article discusses the pathogenesis of glaucoma especially when associated with diabetes mellitus and how this knowledge can help decrease the burden of loss of vision in diabetic patients due to Glaucoma.
\end{abstract}

Keywords: Blindness, Diabetes mellitus, Glaucoma.

\section{Introduction}

Glaucoma is the second leading cause of irreversible blindness worldwide. ${ }^{1}$ Worldwide more than 60 million people suffer from glaucomatous optic neuropathy with approximately 8.4 million people becoming blind due toglaucoma. ${ }^{2}$ Primary open angle glaucoma (POAG) is the most common type of glaucoma. ${ }^{3}$ Older age, ${ }^{3,4}$ a family history of POAG, ${ }^{5}$ myopia, ${ }^{6}$ central corneal thickness, ${ }^{7}$ and ocular hypertension $^{8,9}$ are relatively consistent risk factors for POAG.

Diabetes mellitus (DM) is a serious and increasingly prevalent medical health problem worldwide due to alterations in the living lifestyle and as age advances. DM is associated with severe acute and chronic complications, which negatively influence both the quality of life and the survival of the affected individuals i.e both morbidity as well as mortality. ${ }^{10}$ Previous published reports suggest diabetes mellitus to be one of the most important risk factor for the development of glaucoma.

\section{Epidemiology}

Over the last decade the prevalence of glaucoma has been reported by different institutes. There have been some differences mainly as a result of different methodologies used by them. There are approximately 11.2 million individuals aged 40 years and above suffering from glaucoma in India. Primary open angle glaucoma is estimated to affect 6.48 million individuals. The estimated number with primary angleclosure glaucoma is 2.54 million. Those with any form of primary angle-closure disease could comprise 27.6 million in number. Majority of the individuals affected with the disease remain aymptomatic and pose great challenge not only in the diagnosis but also in the treatment. ${ }^{11}$

Glaucoma leads to chronic optic neuropathy and is of progressive nature. It is characterized by typical changes in the optic disc and retinal nerve fiber layer
(RNFL) with simultaneous defects in the entire visual field. In such cases the raised intraocular pressure (IOP) is a major risk factor. Glaucoma is ranked as the second major cause of blindness especially in India. About $50 \%$ of the glaucoma patients in the society remain asymptomatic. In India this figure is about $90 \%$. On one hand nearly $50-90 \%$ of true glaucoma patients remain undiagnosed, while on the other hand, nearly half of the "glaucoma patients" using ocular hypotensive medication do not actually require medications or are over-treated. However, it can be easily emphasized that under-diagnosis and over-treatment are commonly reported in glaucoma especially in cases associated with diabetes mellitus. The reported cases may be much higher especially when non-compliant patients are included.

The effects of under-diagnosis have been reported but the effects due to over treatment are detrimental as it increases the treatment cost, affects the quality of life and also exposes patients to the risks of side-effects without much advantage. ${ }^{11}$ Under-diagnosis of glaucoma can be due to patients not consulting their ophthalmologist at all or in time, or the diagnosis missed out by the ophthalmologists. Unfortunately, this issue itself is multifactorial. Many a times the patients do not understand the vital significance of preventive eye care or are not aware of the risk for glaucoma. In other cases, some patients do not have access to professional eye care because of financial constraints or lack of adequate transportation facilities to the referral centre. $^{1}$

DM is associated with various acute and chronic complications that have an adverse effect on the morbidity as well as mortality of those affected. ${ }^{9}$ The rate of prevalence of diabetes among all age groups worldwide reported in the year 2000 was $2.8 \%$ and is estimated to be nearly $4.4 \%$ by $2030 .{ }^{10}$ Some studies have proved that DM is an important risk factor for POAG. ${ }^{12-15}$ However, the relationship between DM and POAG is not well documented and still remains 
controversial. $^{16,17}$ An earlier meta-analysis in 2004 indicated that DM is associated with an increased risk of developing POAG. ${ }^{18}$ However, the various metaanalysis of DM and the risk of POAG did not include any cohort studies. The major disadvantage of crosssectional studies is that they cannot establish a clear relationship between exposure and outcome. Instead, it is recommended to include prospective cohort studies so as to assess the relationship between exposure to diabetes and development of POAG. Various largerscale epidemiological evidence, especially cohort studies of an association between DM and POAG has been proved. ${ }^{15,17,19-23}$

POAG is the most common form of glaucoma seen in the present study in both diabetics $(6.8 \%)$ as well as non-diabetics (3.9\%). Meta-analysis conducted by previous authors found statistically significant association between Diabetes Mellitus and POAG [OR $=1.50,95 \%$ confidence interval $(\mathrm{CI}) 1.16,1.93]$. Neovascular glaucoma has been the second common type of glaucoma found in both diabetics $(1.2 \%)$ as well as non-diabetics $(0.4 \%)$ along with features of pseudo exfoliation especially in non-diabetics. In an extensive epidemiological study carried out in Denmark (1983) about $2.1 \%$ diabetics had NVG. Ocular hypertension was more common in diabetics $(2.9 \%)$ as compared to the non-diabetics $(1.7 \%)$. In the same study the prevalence of ocular hypertension in diabetics reported was $3.0 \%$. Simultaneously, a study conducted in Blue Mountain reported a prevalence of $6.7 \%$ in the diabetics. There has been no association of gender with glaucoma. However, a clear association between neovascular glaucoma and the duration of diabetes has been reported. As per a study conducted by Morrison and Pollack in 2003 the incidence of NVG has been directly related to the duration of diabetes and glycemic control in such patients. ${ }^{24-27}$

Glaucoma is a neurodegenerative disorder of the optic nerve resulting due to death of retinal ganglion cell (RGC) further leading to characteristic patterns of loss of visual field. Though elevated IOP is the primary risk factor for the development of POAG, more than $50 \%$ patients had a screening IOP lower than the below the upper limit of normal $(21 \mathrm{mmHg}){ }^{5}$ Previously, it was believed that the primary mechanism by which glaucoma occurs is due to some mechanical stress resulting due to elevated IOP. Unlike in angle closure glaucoma where narrowing of the iridocorneal angle results in mechanical obstruction of the trabecular meshwork finally blocking the flow of aqueous humor, IOP elevation in POAG is believed to be the result of resistance to the aqueous flow. Though IOP elevation is directly related to RGC death, multiple other mechanisms are thought to contribute to the development of glaucomatous optic neuropathy including genetics, impaired microcirculation, and abnormalities in the pressure of cerebrospinal fluid. ${ }^{28}$ Mechanical stress due to increased IOP is thought to occur primarily at the level of the lamina cribrosa-the point at which the optic nerve fibers penetrate the posterior sclera. ${ }^{59}$ The optic nerve fibers form the axons of the RGCs, but IOP-induced mechanical stress causes posterior bowing and thinning of the lamina, which disrupts axonal transport. ${ }^{29-32}$ As a result, the RGCs undergo apoptotic cell death in conjunction with loss of neuroretinal rim tissue of the optic disc and corresponding enlargement of the optic cup. ${ }^{33}$ Impaired microcirculation is also thought to be a major contributor towards the development of glaucoma. It was first reported by Harrington in 1959, and subsequent studies have provided further evidence that abnormalities in the ocular perfusion may contribute in the development of glaucomatous optic neuropathy, especially when the IOP is normal. ${ }^{34-43}$ More recent studies have focused on the possibility of low cerebrospinal fluid pressure as a contributing mechanism through an increased translaminar pressure gradient which may exacerbate cupping of the optic nerve head. ${ }^{44-47}$ Several hypotheses on biological links between DM and POAG have been proposed. The most important being the presence of long-standing hyperglycemia, along with lipid anomalies may increase the risk of neuronal injury from stress. ${ }^{48}$

Vascular dysregulation has been described in both diabetics as well as in those having glaucoma. Upregulation of nitric oxide, a potent vasodilator, has been reported in both conditions. ${ }^{49-52}$ Nitric oxide not only regulates the vascular tone, but also controls apoptosis. $^{51,53}$ In addition, reactive nitrogen species have been demonstrated to contribute to the inflammatory responses via oxidative stress and optic nerve degeneration. ${ }^{53-55}$ The contributory role of PKC (protein kinase c) in the pathophysiology of diabetic retinopathy has also been established and there is a strong evidence to suggest that elevated PKC may also be associated with abnormalities of matrix metalloprotease in the trabecular meshwork causing impaired aqueous outflow and elevated IOP. ${ }^{47,57,56}$ Besides, overexpression of matrix metallprotease- 9 has been associated with structural optic nerve head changes in diabetic patients, thus providing another potential link between diabetes and glaucoma. ${ }^{57-59}$

Other pathways by which authors have linked diabetes and glaucoma together include glial cell dysfunction and impairment of retrograde axonal transport. ${ }^{57}$ Glial cells, such as astrocytes, are nonneuronal cells that support and protect neurons in the central nervous system, including the retina and optic nerve. Any functional change in these cells has been demonstrated in animal models with diabetes and glaucoma is believed to contribute to neuroinflammatory pathways of apoptosis. ${ }^{60-66}$ In addition, it has been postulated that alterations in connective tissue remodeling due to diabetes may affect both the lamina cribrosa and the trabecular meshwork, thereby potentially increasing susceptibility to 
glaucoma through biomechanical changes at the optic nerve and impairment of aqueous humor outflow affecting the homeostasis of IOP. ${ }^{57}$

The association between DM and POAG may be explained on the basis of remodeling of the connective tissue of the optic nerve head. This remodeling may reduce the compliance at the trabecular meshwork and the lamina cribrosa, resulting in increased IOP and greater mechanical stress on the optic nerve head, respectively. ${ }^{67,68}$ Various studies have proved that diabetes can exacerbate the remodeling of connective tissue thus amplifying the associated biomechanical changes. ${ }^{69}$

The Applicability of the Association for Improved Patient Care and Early Diagnosis: Glaucoma as is well known is the third leading cause of blindness in India. According to NPCB-WHO survey carried out from 1986 to 1989, glaucoma accounts for $5.80 \%$ of the total blindness in India. Most epidemiological studies in India have focused on detection of primary open-angle glaucoma. However, it has been observed that in people belonging to the oriental races including India, primary angle closure glaucoma accounts for nearly $30 \%$ of all cases of glaucoma.

A serious look into the number of persons who are blind or heading towards blindness due to glaucoma in those aged more than 50 years gives an inkling of the gravity of this problem. Late diagnosis is the main hindrance in preventing blindness as a result of glaucoma. Majority of the people, particularly in the rural and belonging to the remote areas are detected so late that by that time vision in one of their eyes has already been lost with a significant diminished vision in the other eye. Therefore, it becomes mandatory that the PMOAs, Medical officers posted in the PHCs and the ophthalmologists working in district hospitals should diagnose patients suffering from glaucoma at early stages. This can be achieved by examining the fundus for optic disc changes, measuring intraocular pressure for a rise in the level, and by careful charting of the visual field. Topical eye drops should be started only when the diagnosis has been amply confirmed by an experienced ophthalmologist.

Diabetes forms a major part of a large global epidemic of non-communicable diseases. It has now become a major public health challenge across the entire world. This alarming scenario led the Indian Government to start the National diabetes control programme as a major project during the seventh five year plan in 1987. This project was started in some districts of Tamil Nadu, J \& K and Karnataka. However, due to paucity of funds this programme could not be expanded further in the remaining states.

The main objectives of the programme were. ${ }^{70}$

1. Prevention of diabetes through identification of high-risk subjects and early intervention in the form of health education;
2. Early diagnosis of disease and appropriate treatment;

3. Reduction of morbidity and mortality especially in the high-risk groups;

4. Prevention of acute and chronic metabolic, cardiovascular, renal and ocular complications of the disease;

5. Providing equal opportunities for physical attainment and scholastic achievement for the diabetic patients; and

6. Rehabilitation of those partially or totally handicapped individuals affected with diabetes.

Considering the ever-increasing burden of diabetes mellitus, a health system strengthening approach with standards of care at all levels, nationally accepted management protocols and regulatory framework are the need of the hour.

\section{Conclusion}

Both diabetes and glaucoma represent significant public health issues in the present era. Several epidemiologic studies have confirmed that diabetic individuals are at a very high risk for the development of glaucoma with pathophysiologic similarities to support a strong association between these two conditions. ${ }^{60-82}$ Considering the common pathogenesis of both the chronic diseases as well as the disease process an early diagnosis of both conditions is essential.

It is thus suggested that multidisciplinary approach to the patient is essential by achieving the goal at the tertiary level and also at the grass root level so that a decrease in the burden occurs. Further improvement in the prognosis of both diabetes and glaucoma can be achieved.

Conflicts of Interest: There are no conflicts of interest

\section{References}

1. Quigley HA. Number of people with glaucoma worldwide. Br J Ophthalmol. 1996;80(5):389-393.

2. Cook C, Foster P. Epidemiology of Glaucoma: What's new? Can J Ophthalmol. 2012;47(3):223-226.

3. Peters D, Bengtsson B, Heijl A (2013) Lifetime Risk of Blindness in Open-Angle Glaucoma. Am J Ophthalmol. 2013;156(4):724-30.

4. Leske MC, Connell AM, Schachat AP, Hyman L (1994) The Barbados Eye Study. Prevalence of open angle glaucoma. Arch Ophthalmol. 1994 Jun;112(6):821-9.

5. Sommer A, Tielsch JM (1996) Risk factors for openangle glaucoma: the Barbados Eye Study. Arch Ophthalmol. 1996;114(2):235.

6. Topouzis F, Wilson MR, Harris A, Founti P, Yu F, et al. (2011) Risk factors for primary open-angle glaucoma and pseudoexfoliative glaucoma in the Thessaloniki eye study. Am J Ophthalmol. 2011;152(2):219-228.

7. Francis BA, Varma R, Chopra V, Lai MY, Shtir C, et al. (2008) Intraocular pressure, central corneal thickness, and prevalence of open-angle glaucoma: the Los Angeles Latino Eye Study. Am J Ophthalmol. 2008;146(5):741-6. 
8. Heijl A, Leske MC, Bengtsson B, Hyman L, Bengtsson $\mathrm{B}$, et al. (2002) Reduction of intraocular pressure and glaucoma progression: results from the Early Manifest Glaucoma Trial. Arch Ophthalmol. 2002;120(10):126879.

9. Kass MA, Heuer DK, Higginbotham EJ, Johnson CA, Keltner JL, et al. (2002) The Ocular Hypertension Treatment Study: a randomized trial determines that topical ocular hypotensive medication delays or prevents the onset of primary open-angle glaucoma. Arch Ophthalmol. 2002;120(6):701-13.

10. Vigneri P, Frasca F, Sciacca L, Pandini G, Vigneri R (2009) Diabetes and cancer. Endocr Relat Cancer. 16(4):1103-1123.

11. George R, Ve RS, Vijaya L. (2010) Glaucoma in India: estimated burden of disease. J Glaucoma. 2010;19(6):391-7.

12. Wild S, Roglic G, Green A, Sicree R, King H (2004) Global prevalence of diabetes: estimates for the year 2000 and projections for 2030. Diabetes Care. 27(5):10471053.

13. Dielemans I, de Jong PT, Stolk R, Vingerling JR, Grobbee DE, et al. (1996) Primary open-angle glaucoma, intraocular pressure, and diabetes mellitus in the general elderly population. The Rotterdam Study. Ophthalmology. 103(8):1271-1275.

14. Chopra V, Varma R, Francis BA, Wu J, Torres M, et al. (2008) Type 2 diabetes mellitus and the risk of openangle glaucoma the Los Angeles Latino Eye Study. Ophthalmology. 115(2):227-232.

15. Pasquale LR, Kang JH, Manson JE, Willett WC, Rosner BA, et al. (2006) Prospective study of type 2 diabetes mellitus and risk of primary open-angle glaucoma in women. Ophthalmology. 113(7):1081-1086.

16. Klein BE, Klein R, Jensen SC (1994) Open-angle glaucoma and older-onset diabetes. The Beaver Dam Eye Study. Ophthalmology. 101(7):1173-1177.

17. de Voogd S, Ikram MK, Wolfs RC, Jansonius NM, Witteman JC, et al. (2006) Is diabetes mellitus a risk factor for open-angle glaucoma? The Rotterdam Study. Ophthalmology. 113(10):1827-1831.

18. Tielsch JM, Katz J, Quigley HA, Javitt JC, Sommer A (1995) Diabetes, intraocular pressure, and primary open1angle glaucoma in the Baltimore Eye Survey. Ophthalmology. 102(1):48-53.

19. Wise LA, Rosenberg L, Radin RG, Mattox C, Yang EB, et al. (2011) A prospective study of diabetes, lifestyle factors, and glaucoma among AfricanAmerican women. Ann Epidemiol. 21(6):430-439.

20. Newman-Casey PA, Talwar N, Nan B, Musch DC, Stein JD (2011) The relationship between components of metabolic syndrome and open-angle glaucoma. Ophthalmology. 118(7):1318-1326.

21. Ellis JD, Evans JM, Ruta DA, Baines PS, Leese G, et al. (2000) Glaucoma incidence in an unselected cohort of diabetic patients: is diabetes mellitus a risk factor for glaucoma? DARTS/MEMO collaboration. Diabetes Audit and Research in Tayside Study. Medicines Monitoring Unit. Br J Ophthalmol. 84(11):1218-1224.

22. Welinder LG, Riis AH, Knudsen LL, Thomsen RW (2009) Diabetes, glycemic control and risk of medical glaucoma treatment: A population-based casecontrol study. Clin Epidemiol. 2009;1:125-131.

23. Motsko SP, Jones JK (2008) is there an association between hypothyroidism and open-angle glaucoma in an elderly population? An epidemiologic study. Ophthalmology. 115(9):1581-1584
24. Bonovas S, Peponis V, Filioussi K (2004) Diabetes mellitus as a risk factor for primary open-angle glaucoma: a meta-analysis. Diabet Med. 21(6):609-614.

25. Mitchell P, Smith W, Attebo K, Healey PR. 1996. Prevalence of open-angle glaucoma in Australia. The Blue Mountains Eye Study. Ophtalmology. 1996;103(10):1661-1669.

26. Morrison JC, Pollack IP. 2003. Neovascular glaucoma (Chapter 21). Glaucoma Science and Practice, 1st ed. New York: Thieme Medical Publishers; pp. 226-236.

27. Welinder, L.G, Ander H Riis, Lars L Knudsen et al. 2009. Diabetes, glycemic control and risk of medical glaucoma treatment: A population-based case-control study. Published Date October 2009:1;125-131.

28. Weinreb RN, Aung T, Medeiros FA. The pathophysiology and treatment of glaucoma: a review. JAMA. 2014;311(18):1901-1911.

29. Quigley HA, Addicks EM, Green W, et al. Optic nerve damage in human glaucoma, II: the site of injury and susceptibility to damage. Arch Ophthalmol. 1981;99(4):635-649.

30. Burgoyne CF, Downs JC, Bellezza AJ, et al. The optic nerve head as a biomechanical structure: a new paradigm for understanding the role of IOP-related stress and strain in the pathophysiology of glaucomatous optic nerve head damage. Prog Retin Eye Res. 2005;24(1):39-73.

31. Quigley HA, McKinnon SJ, Zack DJ, et al. Retrograde axonal transport of BDNF in retinal ganglion cells is blocked by acute IOP elevation in rats. Invest Ophthalmol. Vis Sci. 2000;41(11):3460-6.

32. Fechtner RD, Weinreb RN. Mechanisms of optic nerve damage in primary open angle glaucoma. Surv Ophthalmol. 1994;39(1):23-42.

33. Quigley HA, Nickells RW, Kerrigan LA, et al. Retinal ganglion cell death in experimental glaucoma and after axotomy occurs by apoptosis. Invest Ophthalmol. Vis Sci. 1995;36(5):774-786.

34. Harrington DO. The pathogenesis of the glaucoma field: Clinical evidence that circulatory insufficiency in the optic nerve is the primary cause of visual field loss in glaucoma. Am J Ophthalmol. 1959;47(5):177-185.

35. Haas JS. Low tension glaucoma. Trans Pac Coast Otoophthalmol Soc Annu Meet. 1962;43:153-160.

36. Chung HS, Harris A, Kagemann L, Martin B. Peripapillary retinal blood flow in normal tension glaucoma. Br J Ophthalmol. 1999;83(4):466-469.

37. Anderson DR. Glaucoma, capillaries and pericytes: 1 . Blood flow regulation. Ophthalmologica. 1996;210(5):257-262.

38. Johnson DG, Drance SM. Some studies on the circulation in patients with advanced open angle glaucoma. Can J Ophthalmol. 1968;3(2):149-153.

39. Tielsch JM, Katz J, Sommer A, et al. Hypertension, perfusion pressure and primary open-angle glaucoma. A population-based assessment. Arch Ophthalmol. 1995;113(2):216-221.

40. Leske MC, Wu SY, Nemesure B, et al. Incident openangle glaucoma and blood pressure. Arch Ophthalmol. 2002;120(7):954-959.

41. Choi J, Jeong J, Cho H, Kook MS. Effect of nocturnal blood pressure reduction on circadian fluctuation of mean ocular perfusion pressure: A risk factor for normal tension glaucoma. Invest Ophthalmol Vis Sci. 2006;47(3):831-836.

42. Leske MC. Ocular perfusion pressure and glaucoma: Clinical trial and epidemiological findings. Curr Opin Ophthalmol. 2009; 20(2):73-78. 
43. Mroczkowska S, Ekart A, Sung V, et al. Coexistence of macro- and micro-vascular abnormalities in newly diagnosed normal tension glaucoma patients. Acta Ophthalmologica. 2012;90(7):e553-559.

44. Morgan WH, Yu DY, Alder VA, et al. The correlation between the cerebrospinal fluid pressure and retrolaminar tissue pressure. Invest Ophthalmol Vis Sci. 1998;39(8):1419-1428.

45. Morgan WH, Yu DY, Cooper RL, et al. The influence of cerebrospinal fluid pressure on the lamina cribrosa tissue pressure gradient. Invest Ophthalmol Vis Sci. 1995;36(5):1163-1172.

46. Wang N, Xie X, Yang D, et al. Orbital cerebrospinal fluid space in glaucoma: the Beijing Intracranial and Intraocular Pressure (iCOP) study. Ophthalmology. 2012;119(10):2065-2073.

47. Ren R, Jonas JB, Tian G, et al. Cerebrospinal fluid pressure in glaucoma: a prospective study. Ophthalmology. 2010;117(2):259-266.

48. Kong GY, Van Bergen NJ, Trounce IA, Crowston JG (2009) Mitochondrial dysfunction and glaucoma. $J$ Glaucoma. 18(2):93-100.

49. Toda N, Nakanishi-Toda M. Nitric oxide: ocular blood flow, glaucoma and diabetic retinopathy. Prog Retin Eye Res. 2007;26(3):205-238.

50. Zheng L, Kern TS. Role of nitric oxide, superoxide, peroxynitrite, and PARP in diabetic retinopathy. Front Biosci (Landmark Ed). 2009(1);14:3974-3987.

51. Cavet ME, Vittitow JL, Impagnatiello F, et al. Nitric oxide (NO): an emerging target for the treatment of glaucoma. Invest Ophthalmol Vis Sci. 2014;55(8):50055015.

52. Husain S, Abdul Y, Singh S, et al. Regulation of nitric oxide production by $\delta$-opioid receptors during glaucomatous injury. PLoS One. 2014;9:e110397.

53. Hara MR, Agrawal N, Kim SF. S-nitrosylated GAPDH initiates apoptotic cell death by nuclear translocation following Siah1 binding. Nat Cell Biol. 2005;7(7):665674.

54. Goldstein IM, Ostwald P, Roth S. Nitric oxide: a review of its role in retinal function and disease. Vision Res. 1996;36(18):2979-2994.

55. Pacher P, Beckman JS, Liaudet L. Nitric oxide and peroxynitrite in health and disease. Physiol Rev. 2007;87(1):315-424. [PubMed: 17237348]

56. Alexander JP, Acott TS. Involvement of protein kinase C in TNFalpha regulation of trabecular matrix metalloproteinases and TIMPs. Invest Ophthalmol Vis Sci. 2001;42(12):2831-2838.

57. Wong VH, Bui BV, Vingrys AJ. Clinical and experimental links between diabetes and glaucoma. Clin Exp Optom. 2011;94(1):4-23.

58. Kuehn MH, Fingert JH, Kwon YH. Retinal ganglion cell death in glaucoma: mechanisms and neuroprotective strategies. Ophthalmol Clin North Am. 2005;18(3):383395.

59. Sivak JM, Fini ME. MMPs in the eye: emerging roles for matrix metalloproteinases in ocular physiology. Prog Retin Eye Res. 2002;21(1):1-14.

60. Nagayach A, Patro N, Patro I. Experimentally induced diabetes causes glial activation, glutamate toxicity and cellular damage leading to changes in motor function. Front Cell Neurosci. 2014;8:355. DOI: 10.3389/fncel.2014.00355.

61. Coleman E, Judd R, Hoe L, et al. Effects of diabetes mellitus on astrocyte GFAP and glutamate transporters in the CNS. Glia. 2004;48(2):166-178.
62. Sandireddy R, Yerra VG, Areti A, et al. Neuroinflammation and oxidative stress in diabetic neuropathy: futuristic strategies based on these targets. Int J Endocrinol. 2014;2014:674987.

63. Scholz J, Woolf CJ. The neuropathic pain triad: neurons, immune cells and glia. Nature Neuroscience. 2007;10(11):1361-1368.

64. Morgan JE. Optic nerve head structure in glaucoma: astrocystes as mediators of axonal damage. Eye (Lond). 2000;(Pt 3B):437-44.

65. Ju WK, Kim KY, Lindsey JD, et al. Intraocular pressure elevation induces mitochondrial fission and triggers OPA1 release in glaucomatous optic nerve. Invest Ophthalmol Vis Sci. 2008;49(11):4903-4911.

66. Chong RS, Martin KR. Glial cell interactions and glaucoma. Curr Opin Ophthalmol. 2015;26(2):73-77.

67. Roberts MD, Grau V, Grimm J, Reynaud J, Bellezza AJ, et al. (2009) Remodeling of the connective tissue microarchitecture of the lamina cribrosa in early experimental glaucoma. Invest Ophthalmol Vis Sci. 50(2):681-690.

68. Johnson EC, Morrison JC, Farrell S, Deppmeier L, Moore CG, et al. (1996) The effect of chronically elevated intraocular pressure on the rat optic nerve head extracellular matrix. Exp Eye Res. 62(6):663-674.

69. Francis-Sedlak ME, Uriel S, Larson JC, Greisler HP, Venerus DC, et al. (2009) Characterization of type I collagen gels modified by glycation. Biomaterials. 30(9):1851-1856.

70. Ministry of Health and Family Welfare. Pilot Phase of the National Programme for Prevention and Control of Diabetes, Cardio-Vascular Diseases, and Stroke Launched. Press Release, 4 January 2008, Available From: http://pib.nic.in/release/release. asp?relid=34389.

71. Zhao D, Cho J, Kim MH, et al. Diabetes, fasting glucose, and the risk of glaucoma: a metaanalysis. Ophthalmology. 2015;122(1):72-78

72. Zhao D, Cho J, Kim MH, et al. Diabetes, glucose metabolism, and glaucoma: the 2005-2008 National Health and Nutrition Examination Survey. PLoS One. 2014; 9(11):e112460.

73. Ko F, Boland MV, Gupta P, et al. Diabetes, triglyceride levels, and other risk factors for glaucoma in the National Health and Nutrition Examination Survey 2005-2008. Invest Ophthalmol Vis Sci. 2016; 57(4):2152-2157.

74. Boland MV, Quigley HA. Risk factors and open-angle glaucoma: classification and application. J Glaucoma. 2007;16(4):406-18.

75. Mitchell P, Smith W, Chey T, et al. Open-angle glaucoma and diabetes: the Blue Mountains eye study, Australia. Ophthalmology. 1997;104(4):712-718.

76. Klein BE, Klein R, Jensen SC. Open-angle glaucoma and older-onset diabetes. The Beaver Dam Eye Study. Ophthalmology. 1994;101(7):1173-1177.

77. Shen L, Walter S, Melles RB, et al. Diabetes pathology and risk of primary open-angle glaucoma: evaluating causal mechanisms by using genetic information. Am J Epidemiol. 2016;183(2):147-55.

78. Pasquale LR, Kang JH, Manson JE, et al. Prospective study of type 2 diabetes mellitus and risk of primary open-angle glaucoma in women. Ophthalmology. 2006;113(7):1081-1086.

79. Dielemans I, de Jong PT, Stolk R, et al. Primary open angle glaucoma, intraocular pressure, and diabetes mellitus in the general elderly population. The Rotterdam Study. Ophthalmology. 1996;103(8):1271-1275. 
80. Tielsch JM, Katz J, Quigley HA, et al. Diabetes, intraocular pressure, and primary open-angle glaucoma in the Baltimore Eye Survey. Ophthalmology. 1995;102(1):48-53.

81. De Voogd S, Ikram MK, Wolfs RC, et al. Is diabetes mellitus a risk factor for open-angle glaucoma? The Rotterdam Study. Ophthalmology. 2006;113(10):182731.

82. Chopra V, Varma R, Francis BA, et al. Type 2 Diabetes Mellitus and the Risk of Open-angle Glaucoma: The Los Angeles Latino Eye Study. Ophthalmology. 2008;115(2):227-232.

83. Graw J, Welzl G, Ahmad N, et al. The KORA Eye Study: a population-based study on eye diseases in Southern Germany (KORA F4). Invest Ophthalmol Vis Sci. 2011;52(10):7778-7786.

84. Ellis JD, Evans JM, Ruta DA, et al. Glaucoma incidence in an unselected cohort of diabetic patients: is diabetes mellitus a risk factor for glaucoma? DARTS/MEMO collaboration. Diabetes Audit and Research in Tayside Study. Medicines Monitoring Unit. Br J Ophthalmol. 2000;84(11):1218-1224.

85. Wise LA, Rosenberg L, Radin RG, et al. A prospective study of diabetes, lifestyle factors, and glaucoma among African-American women. Ann Epidemiol. 2011;21(6):430-439.

How to cite this article: Tripathi $\mathrm{S}$, Srinivasan M. Glaucoma and diabetes: A review. Ind J Clin Exp Ophthalmol. 2018;4(3):294-299. 